\title{
Implications of Downside Beta: Empirical Evidence of Four Asian Tigers
}

\author{
Charlie Charoenwong \\ Nanyang Technological University, Jurong, Republic of Singapore \\ Chee $\mathrm{Ng}$ \\ Fairleigh Dickinson University, Madison, USA
}

\begin{abstract}
This paper uses empirical data from Singapore, South Korea, Hong Kong, and Taiwan to test the appropriateness of using downside beta as a measure of systematic risk. Contrary to what is found in the previous study on the U.S. market, our findings suggest that the explanatory power of downside beta to the stock returns in these markets is weak. This may be due to the positive skewness of stock returns in emerging markets in Asia. In addition, sorting stocks by downside beta does not lead to the capturing of additional priced risk than sorting on regular market beta. This result remains consistent after controlling for abnormal stock returns in the calendar month of January.
\end{abstract}

Keywords: Sharpe-Lintner-Mossin beta, semivariance beta, asymmetric response model beta, downside covariance beta

\section{Introduction}

Variance of a stock is the expected value of the average squared deviation from the mean return. It takes into account both tails of the return distribution. Assuming symmetric distribution, variance proves to be a valid and appropriate measure for systematic risk. However, a well known objection to using variance is that the assumption of symmetric return distribution is almost always violated. Moreover, rational investors are more concerned about downside risk rather than upside risk. These reasons cast doubts on the accuracy and relevance of using variance to measure risk.

Downside beta measures the sensitivity of stock returns to the overall market when the market is experiencing a downturn. In this paper, we introduce three ways of defining and calculating downside beta: (1) Semivariance beta; (2) Asymmetric Response Model (ARM) beta; and (3) Downside Covariance (DC) beta. In spite of its complexity, downside beta seems to be a more relevant measure of systematic risk.

In Markowitz's (1959) findings, portfolio analysis using semivariance tends to produce more efficient portfolios. A series of post-1960 researches support Markowitz's proposition. Specifically, Hogan and Warren (1974) prove that the fundamental structure of CAPM continues to hold when standard deviation is substituted with semivariance. This includes: (1) the linear relationship between the equilibrium expected return of efficient portfolio and portfolio risk; and (2) the linear relationship between the equilibrium expected return of an individual security and relative security risk. Market equilibrium model using downside semivariance, as

Charlie Charoenwong, Associate Professor of finance, Nanyang Business School, Nanyang Technological University.

Chee Ng, Professor of finance, Economics, Finance and International Business, Fairleigh Dickinson University.

Correspondence concerning this article should be addressed to Chee Ng, Madison, NJ, USA. E-mail: chee_ng@fdu.edu. 
found by Bawa and Lindenberg (1977), does not require the traditional assumption of normal distribution of security returns.

Nevertheless, using semivariance has its limitations as well. In particular, downside beta only explains $15 \%-20 \%$ of the cases for equity pricing, whereas regular beta explains $50 \%-80 \%$, as established by Pedersen and Hwang (2007). Downside beta does not necessarily better explain cross-sectional returns in the emerging market than regular beta (Galagedera \& Brooks, 2007). In addition, Galagedera (2008) establishes that the relationship between regular beta and downside beta very much depends on the standard deviation of market returns and the difference between threshold rates of return from the risk-free rate.

Pedersen and Satchell (2000) use a regression model to calculate ARM beta. Unfortunately their model fails to eliminate upside risk completely from the calculation, and therefore ARM beta is not a pure form of downside beta. As a result we do not expect ARM beta to better explain stock returns than regular beta. Ang, Chen, and Xing (2006) defines DC beta to be the standardized covariance in a market downswing, which excludes the central tendency of losses in the definition of risk. As a result, DC beta is not consistent with the traditional mean-semivariance framework.

This paper seeks to extend the research by Post, Vliet, and Lansdorp (2009) to Singapore, South Korea, Hong Kong, and Taiwan in investigating the role of downside beta and its robustness as a measure of systematic risk. Rising consumption and robust economic growth in these emerging markets in Asia have made them increasingly attractive to fund managers looking to diversify their investments into these prospective regions. Hence, our findings will have important implications to these investors. Using stock market data from 1980 to 2009, we calculate estimates of regular beta and various estimates of downside beta for each individual stock and subsequently form stock portfolios based on these estimates. We then analyze the betas and cross-sectional return spreads of these portfolios across the four countries. We find that regular beta is the most appropriate measure of systematic risk in the four emerging markets in Asia. This is observed through the higher positive mean return spreads obtained when sorting on regular beta, even after controlling for the other downside betas. Sorting stocks by semivariance beta does not lead to capturing additional priced risk than sorting on regular beta. Though the results for ARM beta seems to show similar pattern as those of regular beta after the double sorting procedure, regular beta emerges to be a more appropriate measure of systematic risk in these emerging markets. DC beta does not capture additional priced risk as compared to other betas. As such, DC beta is generally not a relevant measure of systematic risk in the emerging markets in Asia. The results remain consistent after controlling for January effect.

Later sections of this paper are structured as follows. Section two discusses our data and sample. Section three explains our methodology in three sub-sections: the first part introduces the various ways to define and estimate the regular beta and downside betas which include semivariance beta, ARM beta, and downside covariance beta; the second part explains the formation of our stock portfolios and the various sorting techniques used to isolate the effects of the beta; and the third part describes our testing on the robustness of the downside betas after controlling for the January effect. Section four summarizes our findings and discusses its implications. Section five discusses the limitations of our study and the final section concludes our research and suggests directions for further researches.

\section{Data and Samples}

We select common stocks listed on the Singapore Stock Exchange (SGX), Taiwan Stock Exchange Corp 
(TSEC), Hong Kong Stock Exchange (HKEX), and Korea Stock Exchange (KSE). We use total return index of market value-weighted indices: Straits Time Index (STI), Taiwan Stock Exchange Index (TAIEX), Hang Seng Index (HSI), and Korea Composite Stock Price Index (KOSPI) as proxy for market returns. Table 1 shows the 1990-2008 portion of the market profile for each of the countries (see Table 1).

Our sample excludes REITs, ADRs, and foreign stocks. We require the stocks from each market (1) to be still actively trading at the time of the data collection; and (2) to have at least 260 consecutive weeks of data available (for beta estimation). After the initial data requirements are met, we then select 100 stocks with the earliest trading records from each market to conduct our analysis.

Weekly Total Return Index (RI) and Volume Traded (VO) for the time period of 1st January 1980 to 12th October 2009 are retrieved from DataStream. According to DataStream, RI is calculated using the following formula:

$$
R I_{t}=R I_{t-1} * \frac{P_{t}+D_{t}}{P_{t-1}}
$$

where:

$P_{t}=$ price on day $t$;

$D_{t}=$ dividend payment associated with ex-date $t$.

Weekly Treasury bill data obtainable is too limited to coincide with the weekly stock data. However, the Treasury bill rates in the Asian markets are relatively stable, thus, we have opted to use the nominal stock returns as the direct proxy for excess returns.

\section{Methodology}

\section{Measuring Regular and Downside Beta}

This section introduces the formal definition of the various betas used in our analysis and the methods in which each of these betas are calculated.

Regular beta. Regular beta or market beta measures the sensitivity of stock return to the overall market. It assumes an equal assignment of weights to upward and downward deviation from the mean. Regular Beta ( $\beta$ reg) is computed using the linear regression of the return of each individual stock (Ri) against the stock market return (RM).

$$
R_{i, t}=\alpha_{i}+\beta_{\text {reg }, i}\left(R_{M, t}\right)+\varepsilon_{i}^{1}
$$

The regression line is call the Security Characteristic Line and the variables $\alpha_{i}$ and $\varepsilon_{i}$ is the intercept (pricing errors) of the regression line and the error term respectively.

Semivariance beta. Semivariance measures the average squared downward deviation from a return threshold. Hogan and Warren (1974) and Bawa and Lindenberg (1977) replace variance in the traditional CAPM with semivariance using a value of zero for their return threshold. In other words, their model is only concerned with negative market returns. Applying semivariance retains the fundamental structure of the CAPM, i.e., the linear relationship between portfolio return and estimated portfolio risk. By replacing variance with semivariance, semivariance beta becomes the relevant risk measure for individual stocks. Semivariance beta is calculated using the following formula:

\footnotetext{
1 The Security Characteristics Line is formerly expressed as: $R_{i, t}-R_{f, t}=\alpha_{i}+\beta_{\text {reg,i }}\left(R_{M, t}-R_{f, t}\right)+\varepsilon_{i}$, under the assumption of $R_{f, t}=R_{f}$, equation reduces to: $R_{i, t}=\alpha_{i}+\beta_{\text {reg }, i}\left(R_{M, t}\right)+\varepsilon_{i}$.
} 
Table 1

Profile of the Markets

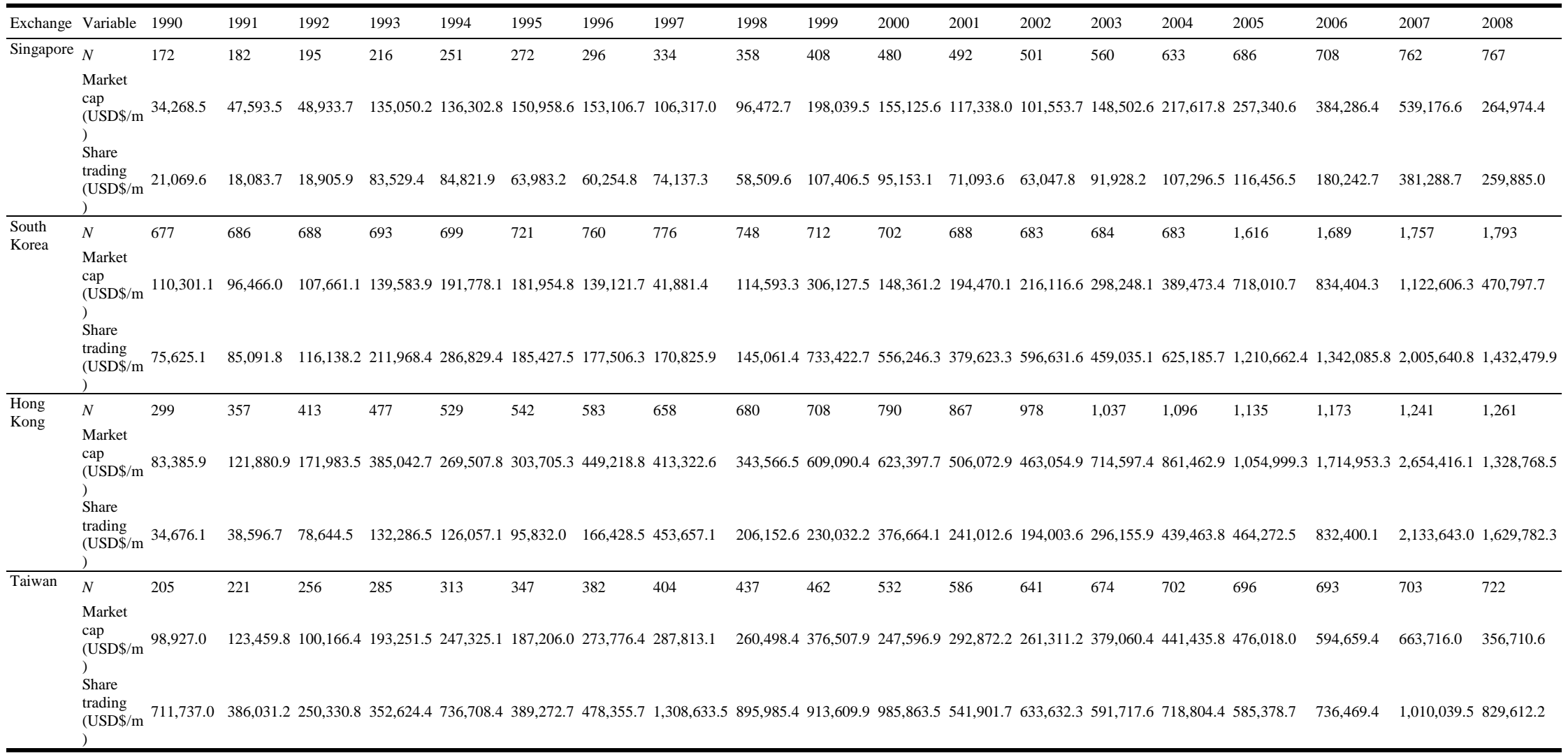

Notes. This table reports the 1990 to 2008 portion of the market profile for Singapore, South Korea, Hong Kong, and Taiwan. $N$ represents the number of companies listed on each exchange. Source: World Federation of Exchanges. 


$$
\beta_{S V, i}=\frac{E\left(R_{M} R_{i} \mid R_{M} \leq 0\right)}{E\left(R_{M}^{2} \mid R_{M} \leq 0\right)}
$$

The numerator represents downside covariance between stock return $R_{i}$ and market return $R_{M}$. It measures the co-movement of the stock return and market return when the market is experiencing a downturn. The denominator of the expression represents semivariance, or second order lower partial moment of the market. Similar to regular beta, this semivariance beta estimates how much a stock contributes to the semivariance of a portfolio.

Asymmetric Response Model (ARM) beta. Pedersen and Satchell (2000) discuss the Asymmetric Response Model expressed using the following formula:

$$
R_{p}(t)=\alpha_{p}+\beta_{1 p} R_{m}^{-}(t)+\beta_{2 p} R_{m}^{+}(t)+\pi_{p} \delta(t)+\varepsilon_{p}(t)
$$

where $R_{p}(t)$ refers to excess return of portfolio $p ; R_{m}^{-}(t)$ and $R_{m}^{+}(t)$ represent the upside and downside excess return of the portfolio respectively. $\delta(t)$ is an index function for market return equal or higher than the risk free rate, and $\varepsilon_{p}(t)$ is the random error. The two coefficients, $\beta_{1 p}$ and $\beta_{2 p}$, indicate the asymmetric nature of excess market returns and allow for stock returns to react varyingly during market upswing and downswing.

We follow the footnotes from Harlow and Rao (1989) to explain why $\beta_{1 p}$ is the downside beta. Using our notation, we can take expectations of the expression, thus:

$$
\begin{aligned}
E\left(R_{p}\right)= & \alpha_{p}+\beta_{1 p} E\left(R_{m}^{-}\right)+\beta_{2 j} E\left(R_{m}^{+}\right)+\pi_{p} P\left(R_{m}>\tau\right) \\
& =\alpha_{p}+\beta_{1 p} R_{m}\left(P\left(R_{m}^{-}\right)\right)+\beta_{2 j} R_{m}\left(P\left(R_{m}^{+}\right)\right)+\pi_{p} P\left(R_{m}>\tau\right)
\end{aligned}
$$

During a falling market, $E\left(R_{m}^{-}\right)=E\left(R_{m}\right)$ and $E\left(R_{m}^{+}\right)=0$. The ARM beta can be expressed as:

$$
\begin{gathered}
\beta_{A R M, i}=\frac{E\left[R_{m}^{-} R_{i}\right]-E\left[R_{m}^{-}\right] E\left(R_{i}\right)}{E\left[R_{m}^{-2}\right]-E\left(R_{m}^{-}\right)^{2}} \\
=\frac{E\left[R_{M} \mid R_{i} \leq 0\right] \operatorname{Pr}\left[R_{M} \leq 0\right]+E\left[R_{M} \mid R_{M}>0\right] E\left[R_{i} \mid R_{M}>0\right] \operatorname{Pr}\left[R_{M}>0\right]-E\left[R_{M}\right] E\left(R_{i}\right)}{E\left[R_{M}^{2} \mid R_{M} \leq 0\right] \operatorname{Pr}\left[R_{M} \leq 0\right]+E\left(R_{M} \mid R_{M}>0\right)^{2} \operatorname{Pr}\left[R_{M}>0\right]-E\left(R_{M}\right)^{2}}
\end{gathered}
$$

However, during a market upswing, $R_{m}^{-}=E\left[R_{M} \mid R_{M}>0\right]$ takes a non-zero value and thus the equation captures a certain amount of upside risk as well. As a result ARM beta is not a pure form of downside beta.

Using the Center for Research in Security Prices (CSRP) equally-weighted index in the empirical test, Harlow and Rao (1989) conclude that the mean-lower partial moment framework cannot be rejected whereas CAPM is rejected. Another conclusion they draw is that investors seem to define downside risk as deviation from a target rate based on equity market mean returns and not the riskless rate.

Downside Covariance (DC) beta. Ang, Chen, and Xing (2006, p. 5) express downside beta as the standardized covariance in a market downturn:

$$
\begin{gathered}
\beta_{D C, i} \equiv \frac{\operatorname{Cov}\left(R_{i}, R_{M} \mid R_{M} \leq 0\right)}{\operatorname{Var}\left[R_{M} \mid R_{M} \leq 0\right]} \\
=\frac{E\left[R_{M} R_{i} \mid R_{M} \leq 0\right]-E\left[R_{M} \mid R_{M} \leq 0\right] E\left(R_{i} \mid R_{M} \leq 0\right)}{E\left[R_{M}^{2} \mid R_{M} \leq 0\right]-E\left(R_{M} \mid R_{M} \leq 0\right)^{2}}
\end{gathered}
$$

They derive that:

$$
\beta_{S V, i} \equiv \beta_{D C, i}
$$

Only when:

$$
E\left[R_{i} \mid R_{M} \leq 0\right]=\beta_{S V, i} E\left(R_{M} \mid R_{M} \leq 0\right)
$$


However, this condition does not hold when the stock has an asymmetric risk profile. Therefore $\beta_{D C, i}$ differs slightly from $\beta_{S V, i}$.

\section{Portfolio Formation and Sorting}

All the stocks that fulfill our data requirements are sorted based on the various beta and grouped into 10 portfolios consisting of an equal number of stocks and for each portfolio, equally weighted returns are calculated.

To isolate the effects of the different downside risk measures, we apply a double-sorting procedure. We sort stocks first into quintile portfolios based on regular-beta and then subdivide each regular-beta quintile into five portfolios based on three definitions of downside beta separately: semivariance beta, ARM beta, and downside covariance beta. These downside betas are defined in the third part in section three. In addition, we also control for downside risk by first sorting on the three definitions of downside beta and subsequently by sorting on the other evaluated betas. In sum, we generate 12 sets of double-sorted beta portfolios.

\section{Robustness Test}

In the study of Rogalski and Seha (1986) and Rathinasamy and Mantripragada (1996), they investigated on the calendar anomaly in which there is a tendency of the stock market to rise between December 31 and the end of the first week in January. Their results show that returns are significantly higher for small stock portfolios particularly in January. We remove the January returns of all the stocks in our data set to ensure that the stock returns are not driven largely by the abnormal returns in January. This would ensure the accuracy of our various beta estimates. We repeat the steps for the single and double sorting procedures mentioned in the second part in section three on the new data sets and we compare the results with the original ones to check for consistency of our data. The next section discusses the results and implications of our findings.

\section{Results and Discussions}

Table 2 reports the results for single sorted and double sorted procedures arranged by country. Panel A, B, $\mathrm{C}$ and D present the results for Singapore, South Korea, Hong Kong and Taiwan respectively.

We sort the portfolio on each of the betas separately and generate the cross-sectional return spread (mean return spread) and beta spread. However, the various betas are highly correlated which might obscure the differences among them. To isolate the effect of the various risk measures, we perform double sorting procedure of the portfolio.

We first describe the results for single-sorting procedure for the four countries before moving on to discussing the results for the double-sorting procedure. After that, we compare the results across the four countries before moving on to test on the robustness of our data by controlling for January effect.

\section{Single-sorting Procedure}

The first part of Table 2 shows the result for Singapore market. Upon sorting the portfolio based on regular beta, the mean return spread is 0.18 basis points per week, which translates to an annual return spread of $9.41 \%$. The corresponding regular beta spread of 0.87 is produced. Given that the annualized market return was $10.84 \%$ during the sample period, the figures suggest that regular beta is a relevant risk measure in Singapore market. 
Table 2

Single-Sorted and Double-Sorted Beta Portfolios

\begin{tabular}{|c|c|c|c|c|c|c|c|c|}
\hline & \multicolumn{8}{|c|}{ Singapore } \\
\hline & \multicolumn{4}{|c|}{ Mean Return Spread } & \multicolumn{4}{|c|}{ Beta Spread } \\
\hline & $\beta_{R E G}$ & $\beta_{S V}$ & $\beta_{\text {ARM }}$ & $\beta_{D C}$ & $\beta_{R E G}$ & $\beta_{S V}$ & $\beta_{A R M}$ & $\beta_{D C}$ \\
\hline Single sorted & 0.18 & 0.04 & 0.01 & 0.07 & 0.87 & 0.92 & 0.89 & 0.95 \\
\hline \multicolumn{9}{|l|}{ Double sorted: } \\
\hline Controlled for $\beta_{R E G}$ & & -0.08 & 0.04 & 0.00 & & 0.24 & 0.22 & 0.36 \\
\hline Controlled for $\beta_{S V}$ & 0.18 & & 0.18 & 0.10 & 0.28 & & 0.26 & 0.33 \\
\hline Controlled for $\beta_{A R M}$ & 0.02 & -0.09 & & 0.01 & 0.24 & 0.26 & & 0.38 \\
\hline \multirow[t]{4}{*}{ Controlled for $\beta_{D C}$} & 0.10 & -0.05 & 0.10 & & 0.39 & 0.34 & 0.38 & \\
\hline & \multicolumn{8}{|c|}{ South Korea } \\
\hline & \multicolumn{4}{|c|}{ Mean Return Spread } & \multicolumn{4}{|c|}{ Beta Spread } \\
\hline & $\beta_{R E G}$ & $\beta_{S V}$ & $\beta_{\text {ARM }}$ & $\beta_{D C}$ & $\beta_{R E G}$ & $\beta_{S V}$ & $\beta_{\text {ARM }}$ & $\beta_{D C}$ \\
\hline Single sorted & 0.09 & -0.01 & 0.00 & -0.01 & 0.94 & 0.93 & 0.89 & 1.28 \\
\hline \multicolumn{9}{|l|}{ Double sorted: } \\
\hline Controlled for $\beta_{R E G}$ & & -0.10 & -0.02 & -0.04 & & 0.25 & 0.21 & 0.48 \\
\hline Controlled for $\beta_{S V}$ & 0.15 & & 0.11 & 0.07 & 0.27 & & 0.23 & 0.41 \\
\hline Controlled for $\beta_{A R M}$ & 0.04 & -0.09 & & -0.02 & 0.24 & 0.24 & & 0.46 \\
\hline \multirow[t]{4}{*}{ Controlled for $\beta_{D C}$} & 0.07 & -0.04 & 0.05 & & 0.36 & 0.28 & 0.33 & \\
\hline & \multicolumn{8}{|c|}{ Hong Kong } \\
\hline & \multicolumn{4}{|c|}{ Mean Return Spread } & \multicolumn{4}{|c|}{ Beta Spread } \\
\hline & $\beta_{R E G}$ & $\beta_{S V}$ & $\beta_{\text {ARM }}$ & $\beta_{D C}$ & $\beta_{R E G}$ & $\beta_{S V}$ & $\beta_{A R M}$ & $\beta_{D C}$ \\
\hline Single sorted & 0.11 & 0.04 & 0.10 & 0.11 & 0.90 & 0.91 & 0.87 & 1.02 \\
\hline \multicolumn{9}{|l|}{ Double sorted: } \\
\hline Controlled for $\beta_{R E G}$ & & -0.08 & -0.01 & 0.06 & & 0.20 & 0.16 & 0.38 \\
\hline Controlled for $\beta_{S V}$ & 0.17 & & 0.18 & 0.12 & 0.23 & & 0.20 & 0.36 \\
\hline Controlled for $\beta_{A R M}$ & 0.02 & -0.12 & & 0.05 & 0.20 & 0.21 & & 0.39 \\
\hline \multirow[t]{4}{*}{ Controlled for $\beta_{D C}$} & 0.03 & -0.07 & 0.01 & & 0.39 & 0.33 & 0.36 & \\
\hline & \multicolumn{8}{|c|}{ Taiwan } \\
\hline & \multicolumn{4}{|c|}{ Mean Return Spread } & \multicolumn{4}{|c|}{ Beta Spread } \\
\hline & $\beta_{R E G}$ & $\beta_{S V}$ & $\beta_{\text {ARM }}$ & $\beta_{D C}$ & $\beta_{R E G}$ & $\beta_{S V}$ & $\beta_{\text {ARM }}$ & $\beta_{D C}$ \\
\hline Single sorted & 0.05 & -0.01 & -0.01 & -0.02 & 0.47 & 0.54 & 0.51 & 0.64 \\
\hline Double sorted: & & & & & & & & \\
\hline Controlled for $\beta_{R E G}$ & & -0.06 & -0.01 & 0.02 & & 0.18 & 0.15 & 0.31 \\
\hline Controlled for $\beta_{S V}$ & 0.06 & & 0.08 & 0.07 & 0.16 & & 0.14 & 0.24 \\
\hline Controlled for $\beta_{A R M}$ & 0.04 & -0.05 & & 0.03 & 0.14 & 0.14 & & 0.29 \\
\hline Controlled for $\beta_{D C}$ & -0.02 & -0.06 & -0.05 & & 0.24 & 0.21 & 0.23 & \\
\hline
\end{tabular}

Notes. The table reports the mean excess return spread and beta spread for single-sorting and double-sorting procedures arranged by country. Table 2 shows the results for Singapore, South Korea, Hong Kong, and Taiwan markets respectively. Common stocks from each country are sorted into deciles for the single-sorting procedure. The decile portfolios are then sorted on each of the betas. Subtracting the mean excess return of the highest ranked decile with the lowest one presents the mean excess return spread. The table presents value weighted weekly mean return spreads and beta spreads of the decile portfolios sorted according to each of the betas. Double-sorted portfolios are constructed by sorting on three measures of beta after controlling for one beta. Initially common stocks are sorted into quintiles using the control beta. Within each quintile, the stocks are sorted on the evaluated beta. For double-sorting procedure, the table reports value weighted weekly mean return spread and the corresponding beta spread of the relevant beta portfolios. 
If we sort on semivariance beta, it generates a mean return spread of 0.04 basis points per week and an annual return spread of $2.03 \%$. The semivariance beta spread is 0.92 , which is higher than the regular beta of 0.87. However, the higher semivariance beta spread does not translate to a higher mean excess return spread. This suggests that regular beta is a more relevant measure of systematic risk than semivariance beta for Singapore market.

When we sort on ARM beta, it produces a mean return spread of 0.01 and beta spread of 0.89 . The slightly higher beta spread as compared to regular beta does not translate to a larger mean return spread. This is similar in the case of DC beta. It has a higher beta spread of 0.95 as compared to that of the regular beta but the first has a much lower mean return spread than the latter. As such, ARM and DC beta are not better estimates of systematic risk as compared to regular beta. In all, we can imply that regular beta is the more relevant systematic risk measure in Singapore.

South Korea demonstrates similar results as Singapore. Based on the South Korea results (see Table 2), the upside risk captured by regular beta is priced by investors, shown by the higher mean return and beta spreads for regular beta than those of semivariance beta. Sorting on ARM and DC beta results in nearly zero mean return spreads. Therefore, regular beta proves to be the most relevant systematic risk measure in South Korea market.

Look at the results for Taiwan (see Table 2). The results prove to be similar to those of Singapore, except that the beta spreads in Taiwan is lower than those in Singapore, South Korea, and Hong Kong. The results indicate that the risk captured by regular beta is priced by investors, unlike that of semivariance beta. Furthermore, sorting on ARM and DC beta results in negative mean return spreads. Therefore, similar to Singapore and South Korea, regular beta is a better measure of systematic risk in Taiwan.

Hong Kong, however, seems to suggest that regular beta and ARM beta are both good measures of systematic risk. This is different to the results for the other three countries. Despite the lower beta spread, ARM beta captures a similar (only slightly lower) mean return spread than regular beta. The third part of Table 2 shows the figures obtained for Hong Kong.

\section{Double-Sorting Procedure}

We first control for regular beta. The semivariance beta yields a mean spread of -0.08 basis points per week and a beta spread of 0.24 . This suggests that it does not capture significant priced risk captured by regular beta. This is similar for the cases of ARM and DC betas. This seems to imply that regular beta is a more appropriate systematic risk measure. South Korea, Hong Kong, and Taiwan share the same conclusion. However, we can observe that DC beta produces a higher beta spread but low mean return spread. This suggests that DC beta captures additional risk which is not priced.

Upon controlling for semivariance beta, the regular beta a beta spread of 0.28 . As regular beta accounts for both upside and downside risks, it is common that regular beta captures risk beyond semivariance beta. From the mean spread, we can imply that the upside risk is priced, seen from the mean spread of 0.18 basis point per week. As such, regular beta seems to be a more superior measure of systematic risk than semivariance beta. Similar pattern appears in the results for other three markets.

Next we control for ARM beta. The results possess similar trends to those of controlling for regular beta. Semivariance beta yields a negative mean return spread of -0.09 basis points per week, By contrast, the regular beta and DC beta yield slightly positive mean spreads of 0.02 and 0.01 basis points per week respectively. The 
close similarity of results between ARM and regular beta is also evident in other three countries. This suggests the similarity between ARM and regular beta which capture both upside and downside risk.

When controlled for DC beta, the other three betas yield considerably larger beta spreads, which are 0.34 and above, as compared to controlling for the other betas. This suggests that they capture significant systematic risk beyond DC beta. The higher mean spread for regular beta ( 0.10 basis points per week) as compared to that of semivariance beta ( -0.05 basis points per week) indicates that regular beta captures substantial priced risk that is not captured by semivariance beta. Similar results are also apparent in the other three emerging markets. This strengthens our earlier suggestion that regular beta seems to be the most relevant risk measure.

\section{Comparison Across the Four Countries}

Our findings suggest that regular beta is the most appropriate measure of systematic risk in the four emerging markets in Asia. Sorting stocks by semivariance beta does not lead to capturing additional priced risk than sorting on regular beta. Though the results for ARM beta seems to show similar pattern as those of regular beta after the double sorting procedure, regular beta emerges to be a more appropriate measure of systematic risk in these emerging markets. Based on the single-sorted results, DC beta has a relatively higher beta spread as compared to those of other beta but its mean return spread is comparatively lower. This indicates that the additional risk captured by DC beta is not price by investors. Furthermore, after controlling for DC beta, the related beta spreads are relatively higher than after sorting on the other evaluated beta. These imply that the other beta capture significant systematic risk beyond DC beta. As such, DC beta is generally not a relevant measure of systematic risk in the emerging markets in Asia.

One possible reason for the suitability of regular beta as compared to the downside betas as a measure of systematic risk in these markets is based on the research by Bae, Wei, and Lim (2003). The research finds that stock returns in emerging markets tend to be more positively skewed than those in developed markets like the US.

\section{Controlling for January Effect}

To check for the robustness and consistency of the data, we analyze the data after eliminating the January effect. This would allow us to check the reliability of the data. Table 3 shows the results for the analysis.

After removing the January effect from the sample, we observe similar pattern that regular beta seems to be the most relevant measure of systematic risk across the four countries. Sorting on regular beta results in the highest mean return spread. When we perform double-sorting procedure, regular beta is still more appropriate in measuring systematic risk as compared to semivariance beta. When controlled for regular beta, semivariance beta yields non-positive mean return spreads in the four countries. On the other hand, we obtain positive mean return spreads for regular beta after controlling for semivariance beta. We still achieve similar results after controlling for January effect. This indicates the robustness of our data.

The table reports that the beta spreads slightly decrease except for the case of DC beta which beta spreads remain relatively the same. However, we observe a general increase in the mean return spread upon sorting on various betas. This seems to contradict with the expectation that the returns in January are generally larger than other months. As such, removing the January effect would supposedly result in the lower mean return spread. One possible reason for the deviation might be that our portfolio consists of large cap stocks. The January returns are more pronounced for portfolios of small firms than for portfolios of large firms (Keim, 1982). Easterday, Sen, and Stephan (2009) further suggest that January returns decrease monotonically with firm size. 
IMPLICATIONS OF DOWNSIDE BETA: EMPIRICAL EVIDENCE OF FOUR ASIAN TIGERS 263

Table 3

Single and Double-Sorted Beta Portfolios (Controlled for January Effect)

\begin{tabular}{|c|c|c|c|c|c|c|c|c|}
\hline & \multicolumn{8}{|c|}{ Singapore } \\
\hline & \multicolumn{4}{|c|}{ Mean Return Spread } & \multicolumn{4}{|c|}{ Beta Spread } \\
\hline & $\beta_{R E G}$ & $\beta_{S V}$ & $\beta_{\text {ARM }}$ & $\beta_{D C}$ & $\beta_{R E G}$ & $\beta_{S V}$ & $\beta_{\text {ARM }}$ & $\beta_{D C}$ \\
\hline Single sorted & 0.19 & 0.04 & 0.21 & 0.10 & 0.85 & 0.86 & 0.86 & 0.86 \\
\hline \multicolumn{9}{|l|}{ Double sorted: } \\
\hline Controlled for $\beta_{R E G}$ & & -0.08 & 0.06 & 0.03 & & 0.24 & 0.23 & 0.34 \\
\hline Controlled for $\beta_{S V}$ & 0.14 & & 0.19 & 0.08 & 0.28 & & 0.24 & 0.33 \\
\hline Controlled for $\beta_{A R M}$ & 0.01 & -0.10 & & -0.05 & 0.24 & 0.25 & & 0.37 \\
\hline \multirow[t]{4}{*}{ Controlled for $\beta_{D C}$} & 0.09 & -0.04 & 0.07 & & 0.38 & 0.33 & 0.38 & \\
\hline & \multicolumn{8}{|c|}{ South Korea } \\
\hline & \multicolumn{4}{|c|}{ Mean Return Spread } & \multicolumn{4}{|c|}{ Beta Spread } \\
\hline & $\beta_{R E G}$ & $\beta_{S V}$ & $\beta_{\text {ARM }}$ & $\beta_{D C}$ & $\beta_{R E G}$ & $\beta_{S V}$ & $\beta_{\text {ARM }}$ & $\beta_{D C}$ \\
\hline Single sorted & 0.12 & 0.00 & 0.05 & -0.01 & 0.90 & 0.92 & 0.89 & 1.28 \\
\hline \multicolumn{9}{|l|}{ Double sorted: } \\
\hline Controlled for $\beta_{R E G}$ & & -0.12 & -0.05 & -0.01 & & 0.28 & 0.23 & 0.49 \\
\hline Controlled for $\beta_{S V}$ & 0.15 & & 0.12 & 0.00 & 0.27 & & 0.23 & 0.42 \\
\hline Controlled for $\beta_{A R M}$ & 0.02 & -0.15 & & -0.07 & 0.23 & 0.25 & & 0.47 \\
\hline \multirow[t]{4}{*}{ Controlled for $\beta_{D C}$} & 0.13 & -0.04 & 0.05 & & 0.35 & 0.27 & 0.32 & \\
\hline & \multicolumn{8}{|c|}{ Hong Kong } \\
\hline & \multicolumn{4}{|c|}{ Mean Return Spread } & \multicolumn{4}{|c|}{ Beta Spread } \\
\hline & $\beta_{R E G}$ & $\beta_{S V}$ & $\beta_{\text {ARM }}$ & $\beta_{D C}$ & $\beta_{R E G}$ & $\beta_{S V}$ & $\beta_{\text {ARM }}$ & $\beta_{D C}$ \\
\hline $\begin{array}{l}\text { Single sorted } \\
\text { Double sorted: }\end{array}$ & 0.13 & 0.05 & 0.09 & -0.01 & 0.88 & 0.93 & 0.88 & 1.05 \\
\hline Controlled for $\beta_{R E G}$ & & 0.00 & 0.10 & 0.10 & & 0.28 & 0.24 & 0.50 \\
\hline Controlled for $\beta_{S V}$ & 0.10 & & 0.18 & 0.14 & 0.24 & & 0.20 & 0.39 \\
\hline Controlled for $\beta_{A R M}$ & 0.03 & -0.14 & & 0.07 & 0.23 & 0.22 & & 0.44 \\
\hline \multirow[t]{4}{*}{ Controlled for $\beta_{D C}$} & 0.03 & -0.03 & 0.07 & & 0.42 & 0.35 & 0.39 & \\
\hline & \multicolumn{8}{|c|}{ Taiwan } \\
\hline & \multicolumn{4}{|c|}{ Mean Return Spread } & \multicolumn{4}{|c|}{ Beta Spread } \\
\hline & $\beta_{R E G}$ & $\beta_{S V}$ & $\beta_{\text {ARM }}$ & $\beta_{D C}$ & $\beta_{R E G}$ & $\beta_{S V}$ & $\beta_{\text {ARM }}$ & $\beta_{D C}$ \\
\hline Single sorted & 0.08 & 0.03 & 0.06 & 0.00 & 0.46 & 0.52 & 0.49 & 0.68 \\
\hline \multicolumn{9}{|l|}{ Double sorted: } \\
\hline Controlled for $\beta_{R E G}$ & & -0.07 & 0.00 & 0.01 & & 0.18 & 0.14 & 0.33 \\
\hline Controlled for $\beta_{S V}$ & 0.06 & & 0.14 & 0.09 & 0.17 & & 0.15 & 0.25 \\
\hline Controlled for $\beta_{A R M}$ & -0.01 & -0.13 & & 0.02 & 0.14 & 0.15 & & 0.30 \\
\hline Controlled for $\beta_{D C}$ & 0.01 & -0.06 & 0.02 & & 0.24 & 0.20 & 0.22 & \\
\hline
\end{tabular}

Notes. The table reports the mean excess return spread and beta spread for single-sorting and double-sorting procedures arranged by country. Table 3 shows the results for Singapore, South Korea, Hong Kong, and Taiwan markets respectively. The returns for the month of January of the common stocks from each country are excluded from the original sample. The remaining data are sorted into deciles for the single-sorting procedure. The decile portfolios are then sorted on each of the betas. Subtracting the mean excess return of the highest ranked decile with the lowest one presents the mean excess return spread. For single-sorting procedure, the table presents value weighted weekly mean return spreads and beta spreads of the decile portfolios sorted according to each of the betas. After removing the common stocks data for the month of January, double-sorted portfolios are constructed by sorting on three measures of beta after controlling for one beta. Initially common stocks are sorted into quintiles using the control beta. Within each quintile, the stocks are sorted on the evaluated beta. For double-sorting procedure, the table reports value weighted weekly mean return spread and the corresponding beta spread of the relevant beta portfolios. 


\section{Limitations}

\section{Benchmark Indices}

Table 1 shows that number of stocks listed on the four exchanges range from 200 to more than 900 respectively over the years. However, the STI has 30 constituent stocks and HSI 42 stocks, whereas TAIEX and KOSPI include all stocks listed on the respective exchanges. Because of the relatively small number of stocks included, STI and HSI may not be as powerful as the other two benchmark indices.

\section{Sampling}

We have two limitations for sampling. First of all, we select stocks with earliest trading record to ensure the amount of data available is large. Therefore our sample may not a random sample of the stocks in the markets. In addition, we only include stocks that are still actively trading on 12th October 2009, i.e., the date of our data collection. This is to ensure the stock returns we collected are complete. However, this may result in survivorship bias as only companies with strong performance are included.

\section{Time Period of Data Available}

The stock returns data available from the databases only dates back from the 1980s, even though the stock markets we investigate starts before 1980. Thus we may have excluded important bear markets before 1980 which could affect the accuracy of our results.

\section{Further Research}

The data from Asian markets is generally limited to the period after 1990 because of the short history of emerging markets. As the stock markets develop, more data would be available in the future. It is possible that future researches using more data can obtain more conclusive results.

Our sample includes 100 stocks out of all the stocks listed on each exchange. Because of the large number of stocks listed on each exchange, further researches could use larger-size samples for better representative of the market.

In our paper, we choose to ignore the risk-free rate and use zero as the threshold rate for downside beta calculation. In reality, investors may set positive returns as threshold rate. Further researches could use positive returns as well to investigate the explanatory power of downside beta on stock returns.

In addition, we form equal-weighted portfolio after sorting by the betas. For returns calculations, these portfolios tend to assign too high weights to high-price stocks and too low weights to low-price stocks. On the other hand, value-weighted portfolios assign weights more appropriately using market value. Further researches could build on our paper and calculate value-weighted portfolio returns.

Moreover, further researches can perform more stringent robustness tests. For example, stock returns can be sorted on market capitalization and then by betas, or compare returns from periods of high volatility and low volatility.

\section{Conclusions}

This paper extends the research by Post, Vliet, and Lansdorp (2009) on the appropriateness of using downside beta as a measure of systematic risk in Singapore, South Korea, Hong Kong, and Taiwan. We compare the suitability of regular beta, semivariance beta, asymmetric response model beta, and downside covariance beta as the measures of risk in these emerging markets. 
We select common stocks listed on the exchanges in the four countries, namely, SGX, TSEC, HKEX, and KSE. We form a sample of 100 common stocks with the earliest trading records from each market to conduct our analysis. Due to the stability Treasury bill rates in the Asian markets, we use the nominal stock returns as the direct proxy for excess returns. We retrieve the Weekly Total Return Index and Volume Traded from DataStream for the time period of 1st January 1980 to 12th October 2009.

Using the sample, we form dynamic decile portfolios based on regular beta and the three downside betas. Sorting on regular beta yields a higher return spread but slightly lower beta spreads than sorting on semivariance beta. This implies that the additional risk captured by semivariance beta is not priced by investors. In a similar way, ARM and DC beta are not better measures of systematic risk than regular beta.

To disentangle the effects of various betas, we perform double-sorting procedure. The stocks are sorted into quintiles using the control beta. Within each quintile, they are then sorted on the evaluated beta. Regular beta continues to yield a large and positive mean spread and beta spread even after controlling for semivariance, ARM and DC betas. However, after correcting for regular beta, the semivariance and ARM betas cease to generate positive mean spreads; while the mean spread results for DC beta range from negative to positive mean spread across the different countries. This strengthens the earlier suggestion that regular beta outperforms the downside beta as a measure of systematic risk.

After performing these procedures to each of the markets, we test the robustness of our data by removing the stock returns in the calendar month of January. The results remain consistent after controlling for January effect.

Our findings suggest that sorting stocks on downside beta does not lead to capturing additional priced risk than sorting on regular market beta, contrary to what is found in the previous study on the US market. In addition, the explanatory power of downside beta to the stock returns in these markets is weak. This may be due to the positive skewness of stock returns in emerging markets. Therefore, regular beta seems to be a more appropriate measure of systematic risk in emerging markets in Asia.

\section{References}

Ang, A., Chen, J., \& Xing, Y. (2006). Downside risk. Review of Financial Studies, 19(4), 1191-1239.

Bae, K. H., Wei, K. C. J., \& Lim, C. W. (2003). Corporate governance and conditional skewness in the world's stock markets. Asian Institute of Corporate Governance at Korea University Working Paper.

Bawa, V. S., \& Lindenberg, E. B. (1977). Capital market equilibrium in a mean-lower partial moment framework. Journal of Financial Economics, 5(2), 189-200.

Easterday, K. E., Sen, P. K., \& Stephan, J. A. (2009). The persistence of the small firm/January effect: Is it consistent with investors' learning and arbitrage efforts? The Quarterly Review of Economics and Finance, 49(3), 1172-1193.

Estrada, J. (2000). The cost of equity in emerging markets: A downside risk approach. Emerging Markets Quarterly, 4, 19-30.

Galagedera, D. U. A. (2009). An analytical framework for explaining relative performance of capm beta and downside beta. International Journal of Theoretical and Applied Finance, 12(3), 341-358.

Galagedera, D. U. A., \& Brooks, R. D. (2007). Is co-skewness a better measure of risk in the downside than downside beta?: Evidence in emerging market data. Journal of Multinational Financial Management, 17(3), 214-230.

Harlow, W. V., \& Rao, R. K. S. (1989). Asset pricing in a generalized mean-lower partial moment framework: Theory and evidence. Journal of Financial and Quantitative Analysis, 24(3), 285-311.

Harvey, C. (2000). Drivers of expected returns in international markets. Emerging Markets Quarterly, 4(3), 32-48.

Hogan, W. W., \& Warren, K. M. (1974). Toward the development of an equilibrium capital market model based on semivariance. Journal of Financial and Quantitative Analysis, 9(1), 1-11.

Keim, D. B. (1983). Size related anomalies and stock return seasonality: Further empirical evidence. Journal of Financial Economics, 12, 13-32. 
Markowitz, H. M. (1959). Portfolio selection. New Haven, Connecticut: Yale University Press.

Pedersen, C. S., \& Satchell, S. E. (2000). Small sample analysis of performance measures in the asymmetric response model. Journal of Financial and Quantitative Analysis, 35(3), 425-450.

Pedersen, C., \& Soosung, H. (2007). Does downside beta matter in asset pricing? Applied Financial Economics, 17(12), 961-978. Post, T., Vliet, P. V., \& Lansdrop, S. (2009). Sorting out downside beta (p. 18). ERIM Report Series.

Rathinasamy, R. S., \& Mantripragada, K. G. (1996). The January size effect revisited: Is it a case of risk mismeasurement? Journal of Financial and Strategic Decisions, 9(3), 9-14.

Rogalski, R. J., \& Seha, M. T. (1986). The January Size Effect: Anomaly or Risk Mismeasurement? Financial Analysts Journal, 42(6), 63-70. 